\title{
Case report: The girl who did not want to grow tall - a diagnostic dilemma
}

\author{
DMA Dahanayake, NIC Perera, GS Wijetunge
}

\section{Abstract}

Body dysmorphic disorder and eating disorders share the core feature of disturbed body image. Literature on the nature of the relationship between these conditions is inconclusive, but has emphasized on differentiating one from the other, as they respond differently to treatment. Furthermore, co-occurrence of these disorders has been described and is associated with more severe illness. Body dysmorphic disorder is categorized under obsessive compulsive and related disorders. We discuss the diagnostic dilemma posed by a 16 -year old girl who presented with a restricted eating pattern due to intense fear of growing tall, who had co-morbid obsessive compulsive disorder.

Key words: Body dysmorphic disorder, eating disorders, obsessive compulsive disorder

SL J Psychiatry 2018; 9(2): 23-25

\section{Introduction}

Body dysmorphic disorder (BDD) and eating disorders (ED) share the core feature of disturbed body image, and their co-occurrence is associated with more severe illness (1). However, studies on the relationship between BDD and ED are inconclusive (1). BDD is classified under obsessive compulsive and related disorders in diagnostic systems (2).

Literature on ED describes excessive worries and fears of gaining weight. Fear of gaining height is not described in ED. Furthermore, fear of growing tall has not been described as a symptom of BDD, although patients with muscle dysmorphia may have preoccupations about the body being too small.

We present the case of a 16-year old girl who presented with restricted eating patterns due to fear of growing tall. She had co-morbid obsessive compulsive disorder (OCD). The diagnostic and management challenges faced are discussed.

\section{Case Report}

A 16-year old girl was admitted following an aggressive outburst, during which she was physically aggressive towards her family. There was a two year history of school refusal, struggles with recurrent intrusive thoughts and images, along with refusal of certain food items due to fear of growing tall. This was her first presentation to psychiatric services.
She had been functioning satisfactorily until about 2 years prior to the presentation. At puberty, she has become taller than her older sister. She was bullied about her height by her classmates. She withdrew from her peers and her school attendance deteriorated to the point where she stopped attending altogether. She claimed that she had read a book which stated that proteins made a person grow tall until the age of 18 years. Thus she stopped taking protein containing food because she did not want to grow tall, and checked labels of packaged food for protein content. She stopped swallowing saliva as she believed it contained proteins. She kept a handkerchief to collect saliva. She continued to eat other types of food and claimed she would eat proteins once she turns 18, after her growth spurt ends. She measured her height monthly. These thoughts were compatible with overvalued ideation. She did not express excessive concern regarding her weight and was not overly concerned about any perceived flaws in her body shape.

In addition, she had recurrent, intrusive images of sexual themes accompanied by compulsions to utter reassurance. At such times, she appeared to be muttering to self. If this was prevented, she ran to the bathroom to complete the act. She feared a bad outcome if she carried out certain actions.

She lived with her father, older sister and brother-in-law. Her mother was working as a domestic helper in the Middle East. She did not have a good relationship with

This is an open-access article distributed under the terms of the Creative Commons Attribution 4.0 International License, which permits unrestricted use distribution and reproduction in any medium provided the original author and source are credited. 
any of her family. There were high expectations placed on her regarding academic achievements and her family was critical of her failure to cope at school. There was a family history of motor tics in her father and substance use disorder in her extended family. Pre-morbidly, she had an anxious temperament and perfectionist traits.

On examination, she appeared wary and it was difficult to engage with her. Her speech was rational. There was no evidence of thought disorder. Her mood was predominantly anxious. She did not have suicidal ideation. There were no depressive cognitions. As described above, she had obsessions and overvalued ideas. She did not have delusions or hallucinations. She was able to concentrate on tasks. IQ testing revealed a superior non-verbal IQ. Her insight was limited. Her height was 5'7” and BMI was normal. Her physical examination was normal, and investigations including CT scan of the brain were normal.

In the context of fear of gaining height leading to restricted eating patterns, BDD and ED were considered as differential diagnoses, together with co-morbid OCD. Interventions as for an eating disorder were commenced. Sertraline was started for the co-morbid OCD. Her obsessions improved, but she continued to struggle with residual symptoms. Cognitions relating to height were difficult to shift and she adamantly refused to eat food items which she perceived as containing protein. The dose of sertraline was optimized and risperidone was added later to augment the effects of sertraline on obsessive symptoms. Her activities improved, but she continued to refuse protein containing food. Unfortunately, following discharge, she refused to take medication and her obsessions worsened leading to aggressive outbursts. She was re-admitted to the psychiatry unit, but continued to have difficulty with medication adherence upon discharge. She remained distant with the treating team. Her family struggled to contain her behaviours and they remained critical of her. Family sessions were held to offer psycho-education and support.

\section{Discussion}

The challenges faced regarding the diagnosis of this patient were exemplified by the lack of sufficient literature on the relationship between BDD and ED. In addition to disturbed body image being a feature of both conditions, there are other important similarities as well as differences $(1,3)$. Weight concerns are relatively common in BDD and many patients with ED have non-weight related concerns regarding the shape of specific body parts such as thighs or stomach $(4,5)$. Patients with both conditions have ritualistic behaviours and repeated thoughts relating to body image concerns, as well as behaviours aimed to change body appearance, such as restricting food intake and going for surgical procedures (1). However, the sex ratios and comorbidity patterns are different for these conditions and BDD tends to cluster in families with OCD (1). Furthermore, BDD responds to serotonin reuptake inhibitors as well as cognitive behavioural therapy, unlike patients with anorexia who show a less robust response (6-8).

Our patient was diagnosed as having ED because of her eating patterns and related cognitions, despite her primary concern being unrelated to weight. Minimal literature was available on patient presentations related to fear of gaining height. A further complication was the presence of co-morbid OCD, which placed her in the spectrum of conditions including BDD. However, the prominence of restriction of eating was felt to favour a diagnosis of ED.

This case highlights the need for further study in the area of overlap between BDD, ED and obsessive compulsive spectrum disorders.

\section{Declaration of interest}

None declared

DMA Dahanayake, Lady Ridgeway Hospital for Children, Colombo

NIC Perera, National Hospital of Sri Lanka, Colombo GS Wijetunge, Lady Ridgeway Hospital for Children, Colombo

Corresponding author: DMA Dahanayake

Email: dulangid@yahoo.com

http://orcid.org/0000-0002-1740-2183

\section{References}

1. Grant JE, Phillips KA. Is Anorexia nervosa a subtype of body dysmorphic disorder? probably pot, but Read on. Harv Rev Psychiatry 2004; 12(2): 123-126.

2. American Psychiatric Association. Diagnostic and statistical manual of mental disorders. 5th ed. Arlington, VA: American Psychiatric Publishing 2013.

3. Phillips KA, Kim JM, Hudson JI. Body image disturbance in body dysmorphic disorder and eating disorders. Psychiatr Clin N Am 1995; 18: 317-34. 
4. Kittler JE, Menard W, Phillips KA. Weight concerns in individuals with body dysmorphic disorder. Eat Behav 2007; 8(1): 115-20.

5. Gupta MA, Johnson AM. Non weight-related body image concerns among female eating disordered patients and nonclinical controls: some preliminary observations. Int J Eat Disord 2000; 27: 304-9.

6. Phillips KA. Pharmacologic treatment of body dysmorphic disorder: review of the evidence and a recommended treatment approach. CNS Spectrums 2002; 7: 453-60.

7. Neziroglu F, Khemlani-Patel S. A review of cognitive and behavioral treatment for body dysmorphic disorder. CNS Spectrums 2002; 7: 464-71.

8. Peterson C, Mitchell JE. Psychosocial and pharmacological treatment of eating disorders: a review of research findings. J Clin Psychol 1999; 55: 685-97. 